\title{
Letters
}

\section{How should different life expectancies be valued?}

EDITOR-Commissioners of health care have to decide which of the many possible uses of resources should be given priority, given that we cannot afford everything that might do some good for some people. One way of comparing possible investments is to consider cost per life year gained. Extending life from 3 months to 9 months at a cost of $£ 4000$ costs the same per life year gained as extending life by 5 years at a cost of $£ 40$ 000-namely, $£ 8000$. Let's leave quality of life, and comparisons of the benefits of mortality and morbidity aside for the time being.

Our problem is this: should 6 months of life, when that is most of what is left, be valued equally with 6 months that is part of a much longer survival period, or should it be valued as part of the progression to complete recovery? Should the time that is left weigh more heavily the closer a patient is to death? We suggest, for debate, that if life expectancy, including the extension, is less than 6 months then any benefit in terms of life years gained should be trebled, and if it is less than 12 months the benefit should be

\section{Advice to authors}

We receive more letters than we can publish:we can currently accept only about one third. We prefer short letters that relate to articles published within the past four weeks. We also publish some "out of the blue" letters, which usually relate to matters of public policy.

When deciding which letters to publish we favour originality, assertions supported by data or by citation, and a clear prose style. Letters should have fewer than 400 words (please give a word count) and no more than five references (including one to the BMJ article to which they relate); references should be in the Vancouver style. We welcome pictures.

Letters, whether typed or sent by email, should give each author's current appointment and full address. Letters sent by email should give a telephone and fax number when possible. We encourage you to declare any conflict of interest. Please send a stamped addressed envelope if you would like to know whether your letter has been accepted or rejected.

We may post some letters submitted to us on the world wide web before we decide on publication in the paper version. We will assume that correspondents consent to this unless they specifically say no.

Letters will be edited and may be shortened. doubled. This assumes that life becomes more precious the nearer to death one gets: a "duration of life left" effect. Do readers agree with this weighting?

Such weighting assumes adjustment for quality of life. There may also, however, be an effect of brevity of life. Some patients may opt for minimum treatment, such as best supportive care, rather than for a slightly longer life of poorer quality. A patient's attitude may be different, however, if an event such as a family wedding or graduation coincides with the potential extension. Patients who have only a short time left to live may tolerate a poorer quality of life than those who have a longer time, and work has shown that poor states of health become less tolerable the longer they last. ${ }^{1}$ The implication may be that if life is short there should be less downward adjustment for quality in calculations of the quality adjusted life year (QALY).

One assumption here is that the patient is aware of the approximate time left, which is more likely when the life expectancy is shorter. The "duration of life left" effect might also apply towards the end of longer life expectancies, which would have implications for the discounting of future QALYs.

We invite comments, as a letter either to the $B M J$ or direct to Norman Waugh.

Norman Waugh Director

Scottish Health Purchasing Information Centre, Aberdeen AB 15 6RE

David Scott Project leader

Scottish Health Purchasing Information Centre

1 Dolan P. Modelling valuations for health states: the effect of duration. Health Policy 1996;38:189-203.

\section{Carers of patients receiving palliative care}

\section{Social workers bring specialist skills to} care of carers

EDITOR-In one of the articles in the ABC of Palliative Care, Ramirez et al focus on carers. ${ }^{1}$ The Association of Hospice and Specialist Palliative Care Social Workers is alarmed to see the marginal role that the authors give to social workers in the column indicating sources of support for carers. Social workers in palliative care perform many tasks and are often responsible for setting up and running bereavement services. We use counselling skills to support both the patients and their carers, contributing appreciably to their psychosocial support. We have particular skills gained, for instance, in fostering and adoption, which help children come to terms with loss and change, and this is an area of work that is developing rapidly.

We would like to draw the authors' attention to an excellent article on social work in palliative care as it would give them an understanding of the skills that we have and the work we undertake. ${ }^{2}$ In this article, Monroe discusses the social worker's role in the multiprofessional team and details some of the specialist skills that social workers bring to palliative care. She points out that social workers are well placed to look holistically at the needs of the patients and their families. Social workers' training encourages an understanding of social and cultural backgrounds and a knowledge of the law and other social institutions. Monroe uses a case study format to illustrate how this knowledge combined with particular communication skills can help in assessing the family's needs and enabling both the professional team and the family to mobilise resources on their behalf. The Association of Hospice and Specialist Palliative Care Social Workers would be happy to help any readers who would like to broaden their understanding of the role of social workers.

Gill Luff Chair, Association of Hospice and Specialist Palliative Care Social Workers

Cheltenham and Gloucester College of Higher Education, PO Box 220, Cheltenham,

Gloucestershire GL50 2OF

Mary Blanch Vice chair, Association of Hospice and Specialist Palliative Care Social Workers Princess Alice Hospice, Esher, Surrey KT10 8NA

1 Ramirez A, Addington-Hall J, Richards M. ABC of palliative care. The carers. BMJ 1997:316:208-11. (17 January.)

2 Monroe B. Social work in palliative care. In: Doyle D, Hanks GWC, MacDonald N, eds. Oxford textbook of palliative medicine. Oxford: Oxford University Press, 1993:565-73.

\section{Specialised psychosocial care may be needed for carers}

EDITOR-The article on carers in the ABC of Palliative Care discussed the psychosocial needs of carers, but the sources of support seemed limited, suggesting that this support may be from the Macmillan nurses, and bereavement counsellors. ${ }^{1}$

The psychosocial care of patients and families is concerned with the psychological and emotional wellbeing of the patient and their family and carers, including issues of self esteem, insight into and adaptation to the illness and its consequences, communications, social functioning, and relationships. ${ }^{2}$ Thus all professionals involved in the care of the patient and family will provide 
psychosocial care. Some families, however, may require more specialised and skilled specialist psychosocial care. This care will need professionals with further training and experience, including social workers, clinical psychologists, and trained (and supported) counsellors. Specialist providers of palliative care should have such skilled professionals available to help in the direct care of families and to advise and support other members of the interdisciplinary team.

Social workers often provide this specialist psychosocial care and may be involved in the care of a family from the time of diagnosis to bereavement. The social worker may also provide advice and help in arranging financial assistance, as suggested in the article, but they have a greater role as a crucial member of the multidisciplinary team.

David Oliver Consultant in palliative medicine Donal Gallagher Specialist social worker, palliative care social work team

North Kent Healthcare NHS Trust, Sittingbourne, Kent ME10 4NS

1 Ramirez A, Addington-Hall J, Richards M. ABC of palliative care. The carers. BMJ 1998;316:208-11. (17 January.)

2 National Council for Hospice and Specialist Palliative Care Services. Feeling better: psychosocial care in specialist palliative care. NCHSPCS, 1997. Occasional paper 13

\section{New combined hepatitis A and $B$ vaccine}

\section{Risks of viral hepatitis related to travel}

EDITOR-The prevention of infectious diseases in travellers is an important public health measure which receives insufficient emphasis. Although Dedicoat and Ellis mention the importance of preventing the transmission of bloodborne viruses for which no vaccines are currently available, ${ }^{1}$ there are effective vaccines against viral hepatitis.

Around 1.4 million cases of hepatitis A are reported annually, with 350 million carriers of hepatitis B worldwide. Steffen reported the incidence of infection with hepatitis A in unprotected travellers as 3-6 per 1000 travellers per month of travel in a tourist resort, rising to 20 per 1000 per month for those in other settings. ${ }^{2}$ The incidence of hepatitis B was reported as 8-240 per 100000 per month for ex-patriates, which fell by 2-10 times in short term travellers. ${ }^{2}$

The sexual transmission of hepatitis B is well recognised. Recent evidence suggests that advice about safe sex is often ignored by British tourists. One study showed that only $46 \%$ of young travellers having sex with a new partner used a condom. ${ }^{3}$ Other risk factors include exposure to unsterilised medical or dental instruments; use of unscreened blood during medical intervention such as after an accident (the commonest cause of death in travellers); and use of unsterilised equipment used in acupuncture, tattooing, and body piercing (all popular with visitors to developing countries).
British residents made 40 million visits abroad in 1995, an increasing proportion travelling to Africa, Asia, and Latin America. The increasing incidence of viral hepatitis related to travel is worrying. In one region of the United Kingdom travellers accounted for $6 \%$ of all reported cases of hepatitis B in 1981 , for $8 \%$ in 1986, and for $12 \%$ in 1990-4.

Travellers should receive advice and appropriate immunisations well in advance of travelling. Accelerated schedules of administration of combined hepatitis A and B vaccine (Twinrix) are currently being evaluated, which may result in more rapid protection against both hepatitis A and B for those travelling frequently and at short notice.

The use of multivalent vaccines has considerable advantages, including increased compliance and convenience, as well as providing concurrent protection. Monovalent vaccines would be recommended in some circumstances. However, for travellers exposed to a risk of viral hepatitis dual protection may be realised by the use of a bivalent hepatitis $\mathrm{A}$ and $\mathrm{B}$ vaccine, thus reducing the burden of infectious disease in this group.

Jane N Zuckerman Head

Academic Unit of Travel Medicine and Vaccines, Royal Free Hospital School of Medicine, London NW3 2PF

1 Dedicoat M, Ellis C. New combined hepatitis A and B vaccine. $B M J 1$ 997:315:951. (11 October)

Steffen R. Hepatitis A and B: risks compared with other vaccine-preventable disease and immunisations. Vaccine 1993;11:518-20.

3 Ford N, Wiser JR. Risk and liminality. The HIV-related socio-sexual interaction of young tourists. In: Clift S, Page $\mathrm{S}$, eds. Health and the international tourist. London: $\mathrm{S}$, eds. Health and the

Routledge, 1996:152-79.

Boxall E. Universal childhood or adolescent vaccination: consideration. In: Zuckerman AJ, ed. Prevention of hepatiti $B$ in the newborn, children and adolescents. London: Royal College of Physicians, 1996:99-105.

\section{Immunisation is only part of preventing} infectious disease

EDITOR-Dedicoat and Ellis suggest restricting the use of the new combined hepatitis A and $\mathrm{B}$ vaccine (Twinrix) because the number of travellers returning infected with these hepatitides is not such to warrant active immunisation.

The task of preventing infectious disease falls on primary care. Immunisation is only a part of this care. The main thrust of prevention is advice on how to stay healthy abroad. If patients don't come to us for their vaccinations what chance do we have in giving them important advice on how to stay healthy abroad?

Combined and monovalent vaccines exist that can prevent the two most frequently occurring immunisable diseases among travellers-namely, hepatitis A and hepatitis B. Hepatitis B vaccine is a means of preventing a sexually transmitted disease, which is also a severe disease with hepatic sequelae, including primary liver carcinoma. An estimated 850000 deaths annually worldwide are due to hepatitis B related liver cancer. Eighty per cent of all liver cancers are due to hepatitis B virus, which is second only to tobacco as a worldwide carcinogen.
In the United Kingdom the provision of clean water for drinking and washing, modern sewage disposal systems, and greatly increased standards of personal hygiene have reduced the prevalence of hepatitis A. Immunity to the virus is falling, leaving a growing number of susceptible people. Children no longer contract the disease in their early years, when it is mainly asymptomatic, and they are in danger of catching the disease as adults, when sequelae can be considerable.

General practitioners and practice nurses are left with the responsibility of ensuring the best advice is given to travellers. Avoiding infection is the most effective prevention. Vaccination provides a good second line of protection.

Which traveller should, therefore, be immunised against hepatitis A and B? My advice is:

- Short term travellers staying for a month or more

- Long term travellers

- Frequent travellers

- Ex-patriate workers

- Travellers coming in contact with local people-for example, immigrant children visiting their homeland

- Occupational groups such as aid workers, missionaries, healthcare workers, and military and diplomatic staff

- People with risky lifestyles: intravenous drug users, adventurous people risking injury, homosexuals, and men and women with multiple sex partners or whose sexual behaviour is likely to place them at risk

- Chronically ill travellers with underlying health problems that may necessitate seeking medical care abroad.?

George Kassianos General medical practitioner Bracknell, Berkshire RG12 7WW

1 Dedicoat M, Ellis C. New combined hepatitis A and B vaccine. BMJ 1997;315:951. (11 October.)

2 Kassianos G. Immunization, childhood and travel health. 3rd ed. Oxford: Blackwell Healthcare Communications, 1997.

\section{New vaccine is an adjunct, not an} alternative to preventive behaviours

EDitor-Dedicoat and Ellis argue that the use of vaccines should be evidence based, ${ }^{1}$ which is our policy at SmithKline Beecham Pharmaceuticals. Hepatitis A and B are the most frequently occurring immunisable diseases in travellers, threatening more people than typhoid and cholera combined. ${ }^{2}$ Therefore, Twinrix, the world's first combined hepatitis $\mathrm{A}$ and $\mathrm{B}$ vaccine, is a logical choice for travellers who may be at risk of both infections. Contrary to what Dedicoat and Ellis say, the vaccine is not promoted in the lay press. Also, the duration of travel is not disregarded.

Duration of travel is becoming less important when prescribing travel vaccines, particularly hepatitis B vaccine, as people's destinations become more exotic and their behaviours more risky-for example, adventure holidays with the risk of accidents and the attendant risk of parenteral treatments. ${ }^{3}$ Furthermore, people's sexual behaviour on holiday is also changing. ${ }^{3-5}$ The Department of Health guidelines cited by Dedicoat and 
Ellis do not suggest reserving hepatitis B vaccine for travellers spending more than one month in highly endemic areas, and they also recommend that short term tourists who place themselves at risk through their sexual behaviour should protect themselves from hepatitis B when abroad. Duration of travel is even less important for the risk of hepatitis A in areas of medium to high endemicity as the risk exists as soon as a traveller arrives in the area.

Awareness of the risks of injections and adherence to safe sexual practices are important in preventing transmission of hepatitis B virus, as well as HIV and hepatitis C virus, for which no vaccines are currently available. Vaccination provides an opportunity for healthcare workers to reinforce this message, as well as providing the available vaccine protection. Twinrix has not been promoted as an alternative to practising safe sex or cautioning against receiving unsterile medical treatment abroad but as an adjunct to good travel health advice. Such advice not only covers safe sex and advice about sterile needles but also includes safety messages about avoiding insect bites, complying with malaria prophylaxis, and hygienic food and water preparation.

Awareness of Twinrix has served to increase awareness of the risks posed by visiting regions where standards of hygiene and sanitation are not optimal. As a responsible vaccine provider, SmithKline Beecham supports vaccination as an adjunct to the overall health care for travellers, not as an alternative to preventive behaviours.

Karl Birthistle Assistant director, clinical research and development/medical affairs

Alastair Benbow Medical director

Smithkline Beecham Pharmaceuticals, Welwyn

Garden City, Hertfordshire AL7 1EY

1 Dedicoat M, Ellis C. New combined hepatitis A and B vaccine. BMJ 1997;315:951. (11 October.)

2 Steffen R. Risk of hepatitis A in travellers. Vaccine 1992;10(suppl 1):S69-72.

3 Keystone J. Hepatitis $A$ and $B$-the risks to traveller Proceedings report: Joining forces to conquer hepatitis $A$ and $B$. London: Royal College of Physicians, 1996.

4 Gillies P. HIV-related risk behaviours in UK holiday makers. AIDS 1992;6:339-40.

5 Ford N, Erser R. Risk and liminality. The HIV related socio-sexual interaction of young tourists. In: Clift S, Page $\mathrm{S}$, eds. Health and the international tourist. London: Routledge, 1996:152-79.

\section{Topical treatment of erectile dysfunction did not show results}

EDITOR-Last year, Gomaa et al reported a double blind placebo controlled crossover study of a cream containing aminophylline, isosorbide dinitrate, and co-dergocrine mesylate in patients with erectile dysfunction. ${ }^{1}$ We recently repeated their study, with men who complained of erectile failure but were capable of achieving nocturnal or early morning erections or responded favourably to vasoactive intrapenile injection therapy, or both; we gave them cream in the same quantity and proportions as those used by Gomaa et al.
After we had studied 10 patients we stopped the trial because no patient had reported penile erection or any noticeable degree of penile tumescence after application of the cream. We were unable to confirm the favourable results reported by Gomaa et al.

J H Naude Head

Department of Urology, University of Cape Town and Groote Schuur Hospital, Cape Town, South Africa

PJ Le Roux Registrar

Department of Urology, Groote Schuur Hospital

1 Gomaa A, Shalaby M, Osman M, Eissa M, Eizat A, Mahmoud M, et al. Topical treatment of erectile dysfunction: randomised double blind placebo controlled trial of cream containing aminophylline, isosorbide dinitrate, and co-dergocrine mesylate BMJ 1996:312: $1512-5$

\section{Authors defend their study to develop tool to predict falls in elderly people}

EdITOR-Altman ${ }^{1}$ has raised several valid points regarding our study to develop and assess a tool for predicting falls in elderly people (STRATIFY). ${ }^{2}$ As he says, we sought a practical measure that would be simple to use and yet powerful enough to guide nursing practice in the daily care of elderly people. STRATIFY is based on five factors that predict falls in hospital: falls as the presenting complaint, visual impairment, agitation, need for frequent toileting, and a combined Barthel transfer and mobility score of 3 or 4 . We defined "high risk of falling" as any two of the five symptoms. We chose to use falls rather than patients as the unit of analysis on medical grounds. We were interested in a pragmatic tool to predict the risk of any fall, repeated or single.

Altman suggested fitting a multiple logistic regression to the data from phase 1 (a case-control study at St Thomas's Hospital). This gave the following weightings: fall as presenting complaint, 1.20 visual impairment, 1.02, agitation, 2.95, need for frequent toileting, 0.34, and combined Barthel transfer and mobility score of 3 or 4 , -0.81 . A total above 1.6 would indicate a high risk. Such a scale would be awkward in practice and would be dominated by agitation.

As we were convinced that each of the elements made a genuine contribution to the patient's risk of falling, the negative sign for the mobility score makes no sense. It was not borne out by the later studies. The range of weightings for the other four items is large. A simple unweighted score was preferred in the validation studies (cohort studies at St Thomas's Hospital and in Canterbury).

We applied the original STRATIFY and the weighted scale to the case-control study, the local (St Thomas's) cohort, and the remote (Canterbury) cohort (table). STRATIFY had lower sensitivity than the weighted scale but identical specificity in the original case-control study. However, it had better sensitivity and indistinguishable
Sensitivity and specificity of STRATIFY (unweighted and with weighting) for predicting falls in three samples of elderly patients. Figures are percentages $(95 \% \mathrm{Cl})$

\begin{tabular}{|c|c|c|}
\hline Patient group & Sensitivity & Specificity \\
\hline \multicolumn{3}{|c|}{ St Thomas's case-control study ( $\mathrm{n}=116$ falls) } \\
\hline STRATIFY & $50.9(41.4$ to 60.3$)$ & $90.5(83.7$ to 95.2$)$ \\
\hline With weighting & 70.7 (61.5 to 78.8$)$ & 90.5 (83.7 to 95.2$)$ \\
\hline Difference & $-19.8(-27.3$ to -11.9$)$ & $0(-4.5$ to 4.5$)$ \\
\hline \multicolumn{3}{|c|}{ St Thomas's cohort ( $\mathrm{n}=71$ patient-weeks) } \\
\hline STRATIFY & $93.0(84.3$ to 97.7$)$ & $87.6(83.6$ to 91.0$)$ \\
\hline With weighting & 77.5 (66.0 to 86.5$)$ & 90.7 (87.0 to 93.7$)$ \\
\hline Difference & 15.5 (5.8 to 25.9$)$ & $-3.1(-6.5$ to 0.2$)$ \\
\hline \multicolumn{3}{|c|}{ Canterbury cohort (n=79 patient-weeks) } \\
\hline STRATIFY & 92.4 (84.2 to 97.2$)$ & $68.3(63.3$ to 73.1$)$ \\
\hline With weighting & $72.2(60.9$ to 81.7$)$ & $71.1(66.1$ to 73.1$)$ \\
\hline Difference & 20.3 (10.4 to 30.5$)$ & $-2.8(-7.3$ to 1.8$)$ \\
\hline
\end{tabular}

specificity in each of the cohort studies. It seems that there was overfitting in the logistic model. The high weighting given to agitation was not borne out in the later studies. This may have been a chance effect or because a relatively large number of falls in the original case-control study were by a small number of agitated patients. Altman ends by approving our external validation of STRATIFY and calling for further evaluation elsewhere. We hope to continue the process in further cohorts.

P T Seed Lecturer, department of statistics (division of public health sciences)

D Oliver Senior registrar

F C Martin Consultant physician

A H Hopper Consultant physician

Guy's and St Thomas's Medical and Dental School, St Thomas's Hospital, London SE1 7EH

1 Altman D. Study to predict which elderly patients will fall shows difficulty in deriving and validating a model. BMJ 1997;315:1309. (15 November.)

2 Oliver D, Briton M, Seed P, Martin FC, Hopper AH. Development and evaluation of evidence based risk tool (STRATIFY) to predict which elderly patients will fall: case-control and cohort studies. BMJ 1997;315:1049-53. (25 October.)

\section{Deaths related to intrapartum asphyxia}

\section{Audit in one unit found neonatal care to be suboptimal at weekends}

EDitor-Stewart et al reported that an excess of deaths related to intrapartum care occurred outside office hours. ${ }^{1}$ In a recent audit done over four months we found that routine neonatal care on our unit was suboptimal at weekends compared with weekdays. Altogether 760 (82.7\%) of 919 women had their babies examined by a neonatal senior house officer before they were discharged by their obstetrician during weekdays, compared with only $150(53.8 \%)$ of 279 women at weekends. Forty $(14.3 \%)$ women had to wait between two and six hours for their babies to be examined at weekends, compared with 77 (8.4\%) during the week. Our aim should be to deliver the same standard of neonatal care-both acute and non-acute-at all times. This may require increases in the numbers of senior 
house officers working in neonatal units at weekends. Alternatively, an extended role for midwives could include performing routine neonatal examinations. This would free neonatal senior house officers for acute neonatal care, especially at weekends.

S D Ferguson Consultant paediatrician T Gehrke Senior senior house officer in paediatrics Department of Child Health, Royal Gwent Hospital, Newport, Gwent NP9 2UB

I Stewart J, Andrews J, Cartlidge PHT. Number of death related to intrapartum asphyxia and timing of birth in all Wales perinatal survey, 1993-5. BMJ 1995;316:657-60. (28 February.)

\section{Intrapartum death rates in England in} 1993-5 did not show consistent peaks or troughs

EDITOR-We were concerned to read that babies born at night and during the summer in Wales are at increased risk of death due to intrapartum asphyxia. ${ }^{1}$ This suggests that staffing issues may be contributing to these losses.

We have examined the intrapartum death rates in England according to the month of birth over the same period that Stewart et al studied. During this period 11171 stillbirths and 8218 neonatal deaths were notified to the Confidential Enquiry into Stillbirths and Deaths in Infancy. The cause of each death is categorised by the Wigglesworth classification. ${ }^{2}$ This study identified 1380 babies with a birth weight of $>1499 \mathrm{~g}$ who died during labour or within 28 completed days of life due to complications in the intrapartum period. The month of birth of these infants was compared with that of surviving infants. Between 1993 and 1995 the average monthly intrapartum death rate was $0.73 / 1000$ total births, ranging from 0.46 to $1.02 / 1000$ total births. There was no consistent peak or trough in any month over this period (figure). When the data were combined for the three years, August was the month with the lowest rate, but the difference was not significant $\left(\chi^{2}=\right.$ $9.9, \mathrm{P}=0.53,11 \mathrm{df}$ ).

The peak of death rates in the summer ("annual leave effect") and in February and August ("rotational effect") in the Welsh

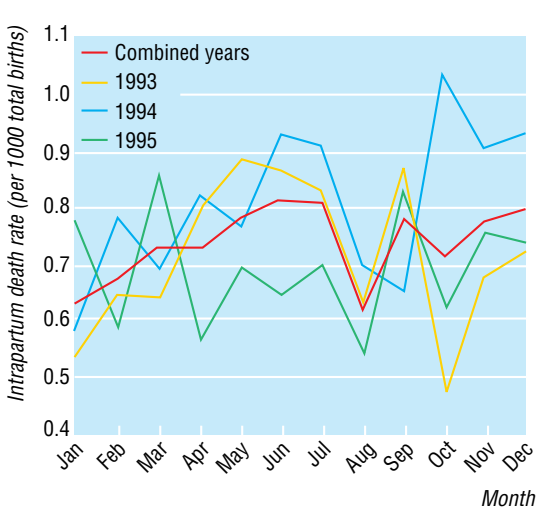

Intrapartum death rates according to month of birth of babies weighing $\geqslant 1500 \mathrm{~g}$ born in England in 1993-5 study may have occurred by chance. Monthly intrapartum death rates are subject to variation. Because the number of births in Wales is only $6 \%$ of those in England, the monthly intrapartum death rates for Wales will necessarily show greater variation. The selective combination of these monthly rates in the Welsh data may have contributed to these surprising findings.

Because details of the time of birth are not routinely collected for all births in England, it is not possible to estimate the risk related to this particular factor. Time of birth was, however, accurately recorded for 1269 of the intrapartum deaths in 1993-5; of these, 606 of the births occurred during the day (9 $00 \mathrm{am}$ to $859 \mathrm{pm}$ ) and 663 occurred at night (900 pm to $859 \mathrm{am}$ ). This can be compared with the figures of 27 and 52 in Wales. ${ }^{1}$ It is unfortunate that the corresponding day and night intrapartum death rates are unavailable for England as they would aid considerably in supporting or refuting the important findings of the Welsh study.

Mary Macintosh Director

Charles Lee IT Specialist

Confidential Enquiry into Stillbirths and Deaths in Infancy, London NW1 5SD

1 Stewart JH, Andrews J, Cartlidge PHT. Numbers of death related to intrapartum asphyxia and timing of birth in all Wales perinatal survey, 1993-5. BMJ 1998;316:657-60. (28 February.)

2 Wigglesworth JS. Monitoring perinatal mortality. Lancet 1980;ii:684-6.

\section{Denominators are needed before} conclusions can be drawn

EDITOR-Stewart et al report twice as many deaths due to intrapartum asphyxia among babies born at night and in July and August as among babies born at other times; they suggest that there is an overreliance on inexperienced staff at these times and that greater supervision by senior staff is required. ${ }^{1}$ In his editorial commenting on this paper Spencer points out that placental abruption, cord prolapse, fetal distress, and placental disease account for many of these intrapartum deaths. ${ }^{2}$

I believe that we need to look at the nature of the disorders involved in these deaths and how they present in order to understand why these events occur and whether they are preventable. In my experience, placental abruption, cord prolapse, and fetal distress often occur at night and there is a considerable delay before the woman presents to the labour ward. This may be because she fears being sent home because she is not in established labour or, in the case of multiparous women, because of difficulties in organising child care at an antisocial hour. Junior and middle grade staff are fairly frequently presented with well advanced catastrophic events at night, to which we respond as well as we would during daylight hours, but the outcome may be predetermined.

No data are available on near-miss situations and the many potentially fatal situations averted both by day and at night. It is detrimental to the morale of junior staff to assert constantly that adverse events occur because of inexperience and lack of supervision. Until denominators are available for the incidence and timing of these events it is unfair to draw such conclusions. I suspect that preventing consultants from taking holidays during the summer and posting them on labour wards at night would do little to reduce the already low intrapartum death rate. While striving to achieve the highest possible standards of obstetric care we must accept that tragic events will always occur in our specialty.

Deirdre J Murphy Specialist registrar in obstetrics and gynaecology Southmead Hospital, Bristol BS10 5NB

1 Stewart JH, Andrews J, Cartlidge PHT. Numbers of deaths related to intrapartum asphyxia and timing of birth in al Wales perinatal survey, 1993-5. BMJ 1998;316:657-60. (28 February.)

2 Spencer JAD. Deaths related to intrapartum asphyxia. $B M J$ 1998;316:640. (28 February.)

\section{Consultant expansion in obstetrics and gynaecology is not fast enough}

EDITOR-Stewart et al's conclusion that a greater input by senior obstetricians may be required at night and during the summer to avert neonatal deaths and stillbirths ${ }^{1}$ echoes the findings of the most recent confidential enquiry into stillbirths and deaths in infancy. ${ }^{2}$ The need for a consultant run obstetric service in order to improve the provision of care led the Royal College of Obstetricians and Gynaecologists to recommend an increase in consultant posts to allow one consultant per 500 deliveries $^{3}$ roughly a 5\% expansion per year. Using these figures, the secretariat of the specialist workforce advisory group issued national training numbers to the regional postgraduate deans to allow recruitment into specialist registrar posts to train clinicians in order that these consultant positions could be filled.

Sadly, consultant expansion in obstetrics and gynaecology is currently running at under $4 \%{ }^{4}$ The failure to reach the $5 \%$ target will lead to clinicians who hold a certificate of completion of specialist training in obstetrics and gynaecology being unable to find consultant posts. How ironic it is that the specialty is producing obstetricians who are well qualified to give senior input on the labour ward but the health service is unwilling or unable to provide consultant posts that would allow them to improve the provision of care for the maternity services.

Murray Luckas Lecturer

Angus Thomson Specialist registrar

Ian Aird Lecturer

Liverpool Women's Hospital, Liverpool L8 7SS

1 Stewart J, Andrews J, Cartlidge PHT. Number of deaths related to intrapartum asphyxia and timing of birth in all Wales perinatal survey, 1993-5. BMJ 1995;316:657-60. (28 February.)

2 Confidential Enquiry into Stillbirths and Deaths in Infancy. 6th Annual report. London: CESDI, 1997.

3 Royal College of Obstetricians and Gynaecologists. Written submission to the Medical Manpower Standing Advisory Committee. London: RCOG, 1992

4 Roval College of Obstetricians and Gynaecologists. Advisory appointments committee returns 1997. London RCOG, 1997. 


\section{Second study shows that octreotide may prevent early rebleeding in cirrhosis}

EDITOR-Jenkins et al have reported a randomised trial showing that long term subcutaneous octreotide together with sclerotherapy significantly reduces the risk of recurrent bleeding from oesophageal varices in liver cirrhosis. ${ }^{1}$

In a double blind placebo controlled pragmatic trial we have found that a 15 day course of subcutaneous octreotide was effective in preventing early rebleeding in cirrhosis. After acute bleeding of the upper digestive tract had been controlled, 262 consecutive patients with cirrhosis were randomised to receive octreotide $100 \mu \mathrm{g}$ subcutaneously three times a day for 15 days $(n=131)$ or placebo $(n=131) . \beta$ Blockers or sclerotherapy or both were added to the trial treatment as soon as possible, our hypothesis being that if octreotide reduced the risk of early rebleeding then $\beta$ blockers or sclerotherapy, or both, could maintain that early beneficial effect. Separate randomisation and analysis were performed according blockers or sclerotherapy or both (101 placebo and 97 octreotide) or not (30 placebo, 34 octreotide). Rebleeding from any source within 15 days was the primary measure of treatment efficacy; rebleeding within 42 days was assessed as a secondary measure. The table summarises the results.

Rebleeding within 15 days among the 198 patients randomised to receive $\beta$ blockers or sclerotherapy, or both, was $27 \%$ $(27 / 101)$ in the placebo group and $15 \%$ $(15 / 97)$ in the octreotide group $(\mathrm{P}=0.05)$; among the 64 who did not receive these treatments they were $33 \%(10 / 30)$ and $47 \%$ $(16 / 34)$ respectively $(P=0.29)$. Corresponding figures in the whole series were $28 \%$ $(37 / 131)$ and $24 \%(31 / 131)$ respectively $(\mathrm{P}=0.40)$. Among the patients who received $\beta$ blockers or sclerotherapy, or both, those to whether patients were eligible to receive $\beta$

taking octreotide showed a significant reduction in rebleeding episodes (18 $v 35$, $\mathrm{P}=0.03)$, blood transfusions (50 v 75 , $\mathrm{P}=0.04)$, and days in hospital (1190 v 1544, $\mathrm{P}<0.0001)$; this beneficial effect was maintained 42 days after randomisation. Mortality was not affected by octreotide in either subgroup of patients.

The 64 patients not randomised to receive $\beta$ blockers or sclerotherapy or both had advanced liver disease ( 35 had ChildPugh grade $\mathrm{C}$ disease; 30 died within 42 days). This might explain the lack of an effect of octreotide in these patients. Octreotide for early rebleeding failed to show any beneficial effect in another trial, ${ }^{2}$ in which $47 \%$ of patients had Child-Pugh grade $\mathrm{C}$ disease. By contrast, patients with grade $\mathrm{C}$ disease made up $28 \%$ of the patients in Jenkins et al's trial, $24 \%$ of the 198 patients benefiting from octreotide in our trial, and $25 \%$ of the patients in another positive trial.

Thus we agree with Jenkins et al that octreotide may prevent early rebleeding in cirrhosis that is not advanced.

Gennaro D'Amico Consultant in gastroenterology Flavia Politi Research fellow

Adele D'Antoni Research fellow

Gandolfo Giannuoli Senior registrar

Linda Pasta Consultant in gastroenterology

Giovanni Vizziani Senior registrar

Mario Traina Senior registrar

Alberto Morabito Associate professor of medical statistics

Luigi Pagliaro Full professor of medicine

Divisione di Medicina, Ospedale V Cervello, 90146 Palermo, Italy

1 Jenkins SA, Baxter JN, Critchley M, Kingsnorth AN, Makin CA, Ellenbogen S, et al. Randomised trial of octreotide fo long term management of cirrhosis after variceal haemorrhage. BMJ 1997;315:1338-41. (22 November.)

2 Primignani M, Andreoni B, Carpinelli L, Capria A, Rocchi G, Lorenzini I, et al and the New Italian Endoscopic Club. Sclerotherapy plus octreotide versus sclerotherapy alone Sclerotherapy in the prevention of early rebleeding from esophagea varices: a randomized, double-blind, place

multicenter trial. Hepatology 1995;21:1322

Besson I, Ingrand P, Person B, Boutroux D, Heresbach D, Bernard P, et al. Sclerotherapy with or without octreotide

Summary of results of randomised controlled trial of octreotide and placebo in 262 patients with cirrhosis

\begin{tabular}{|c|c|c|c|c|c|c|}
\hline \multirow[b]{3}{*}{ Outcome } & & & \multicolumn{4}{|c|}{ Patients given $\beta$ blockers or sclerotherapy, or both } \\
\hline & \multicolumn{2}{|c|}{ Whole population } & \multicolumn{2}{|c|}{ Yes } & \multicolumn{2}{|c|}{ No } \\
\hline & $\begin{array}{l}\text { Placebo } \\
(n=131)\end{array}$ & $\begin{array}{c}\text { Octreotide } \\
(n=131)\end{array}$ & $\begin{array}{l}\text { Placebo } \\
(n=101)\end{array}$ & $\begin{array}{c}\text { Octreotide } \\
(\mathrm{n}=97)\end{array}$ & $\begin{array}{c}\text { Placebo } \\
(\mathrm{n}=30)\end{array}$ & $\begin{array}{c}\text { Octreotide } \\
(\mathrm{n}=34)\end{array}$ \\
\hline \multicolumn{7}{|l|}{ Patients with rebleeding: } \\
\hline Within 15 days & 37 & 31 & 27 & 15 & 10 & 16 \\
\hline Within 42 days & 60 & 48 & 42 & 27 & 18 & 21 \\
\hline \multicolumn{7}{|l|}{ Total rebleeding episodes: } \\
\hline Within 15 days & 47 & 40 & 35 & 18 & 12 & 22 \\
\hline Within 42 days & 82 & 72 & 60 & 38 & 22 & 34 \\
\hline \multicolumn{7}{|l|}{ Blood units given*: } \\
\hline Within 15 days & 107 & 112 & 75 & 50 & 32 & 62 \\
\hline \multicolumn{7}{|l|}{ Deaths: } \\
\hline Within 15 days & 12 & 11 & 3 & 4 & 9 & 7 \\
\hline Within 42 days & 20 & 26 & 8 & 10 & 14 & 16 \\
\hline \multicolumn{7}{|l|}{ Time spent in hospital (days): } \\
\hline All patients & 1977 & 1731 & 1544 & 1190 & 435 & 542 \\
\hline Patients discharged alive $(n=216) t$ & 1665 & 1263 & 1420 & 1028 & 230 & 236 \\
\hline
\end{tabular}

*Total number of units transfused after day 15 was not recorded.

†111 in placebo group and 105 in octreotide group.

\section{New government, same narrow vision}

\section{How hospitals manage emergency} admissions needs to be examined

EDitor-Smith was right to suggest that the debate on the NHS should shift to something more important than waiting lists. ${ }^{1}$ Waiting lists are used by politicians as an indicator of the success or failure of the health service, yet they are merely a measure of how much we as a society wish to spend on the health service. What should be exercising our minds is the ability of hospitals to manage emergency admissions other than those politically important ones occurring over the winter as a result of inclement weather. In 1984 it was recognised that over half of all surgical admissions were emergencies, ${ }^{2}$ and this has not changed; yet patients admitted as a surgical emergency receive a poor service. At worst they may be operated on at inappropriate times by inappropriate surgeons, although we know this is wrong. Alternatively, they may wait for days for expert opinion or investigation and, when finally scheduled for surgery, find themselves jockeying for position on the emergency theatre list, if such a list exists. ${ }^{3}$

Hospitals need to examine what happens to emergency patients after admission with as much attention to detail as they currently examine waiting lists. They could find the results worrying, from both a financial and a quality point of view.

H McFarlane Consultant anaesthetist

Aberdeen Royal Infirmary, Aberdeen AB25 2ZN

1 Smith R. New government, same narrow vision. $B M J$ 1998;316:643. (28 February.)

2 Jones PF. Night and day. BMJ 1984;289:145-6.

3 McFarlane H, Krukowski ZH, Youngson GG, Turner M. Theatre usage for emergency surgery-use or abuse. Health Bull 1997;55:32-43.

\section{Medical profession must change things itself}

EDITOR-Smith's editorial about health policy is timely, but I wonder about relying on the government to ensure good quality care and improve health. ${ }^{1}$ As Smith points out, globalisation and economic forces limit the government's ability to improve health. The recent white and green papers are good examples of the government's limitations. The white paper has not only imposed the principle of fundholding on the unwilling non-fundholding doctors but has broadened the scope of fundholding to include general medical services and prescribing. The green paper, although making much of inequalities, says little about how to reduce them. The fact that New Labour has followed, and extended, the previous government's policies should surely tell us something about the challenges in the new world.

What is needed is not reliance on the government alone but the will and ability to change things ourselves. As responsible professionals we can address certain questions. Why do we continue with outdated practices 
and historical patterns of services? Why do we keep talking about rationing without talking about disinvestment from ineffective, and indeed harmful, practices? Why despite repeated warning about introducing untested technologies does the profession fail to regulate itself? We keep talking about waiting lists without doing any detailed and systematic analysis of the activity in the specialty concerned and whether it is effective and efficient. Why do we keep putting money into new research without ensuring that we put into practice what we already know? Overall, we can ensure that changes are driven by considerations of health, effectiveness, and efficiency. I am not saying that we can solve all the problems ourselves or that more money and hard decisions are not necessary. I believe, however, that we can do a lot ourselves-certainly at the local level.

A useful start will be to change our mindsets and not create polarised positions. Health or health care, money or rationing, them or us, doctors or managers, doctors or nurses, cost or quality, quick or good has to go. Bring in health and health care, money and rationing, them and us, doctors and managers, doctors and nurses, cost and quality, and quick and good. The United Kingdom will then become a healthier place, with or without governments.

Rajan Madhok Honorary clinical reader in public health

Department of Public Health and Primary Care, Faculty of Health, University of Hull, Hull HU8 7RX

1 Smith R. New government, same narrow vision. BMJ 1998;316:643. (28 February)

\section{Health authorities in New Zealand have} spin doctors to produce good news

EDITOR-In his editorial addressing the issue of waiting lists, Smith states that "there is scope to copy New Zealand and do a better job of managing [waiting lists]." ${ }^{1}$ He states further that "New Zealanders have generally welcomed their government's attempt to tackle waiting lists creatively." Britain copies New Zealand's approach at its peril. Smith's claim that we have welcomed our government's approach indicates that he heeds the "good news" machine in our country and has researched the facts insufficiently.

In most areas of need, waiting lists in our country have increased since our health reforms were initiated earlier this decade. Several mechanisms have been set up which superficially suggest that the problem with waiting lists has improved. The facts are to the contrary. Take coronary artery bypass surgery as one example. Patients referred for surgery on the basis of clinical criteria have been removed from the list because their score is $<35$. Retrospective analysis has confirmed that patients referred for bypass surgery with a priority score $<35$ but who no longer qualify for surgery are just as likely to die, have a myocardial infarction, or be readmitted to hospital as are those scoring $>35$. New Zealand's rate of bypass surgery is discordant with that of other Western countries. Little information is available on actual waiting times, and it is not possible to give patients a date for their elective procedures, let alone promise intervention within six months. We fear further manipulation of lists on the basis of points scored rather than clinical need.

The reform process in the United Kingdom has many similarities to that in New Zealand. One area in which New Zealand seems to outshine the United Kingdom is the success of our "good news" machine. Many health authorities and institutions have hired highly paid communications officers to ensure that all news, no matter what its original colour, comes out bleached white.

Smith's editorial highlights difficulties that Britain is having with waiting lists. Do not look to New Zealand as a model to follow.

M Gary Nicholls Professor

A Mark Richards Professor

Peter W Moller Senior lecturer

John M Elliott Senior lecturer

E J Begg Associate professor

Department of Medicine, Christchurch School of

Medicine, Christchurch Hospital, PO Box 4345,

Christchurch, New Zealand

1 Smith R. New government, same narrow vision. $B M$ J 1998;316:643. (28 February)

Most New Zealanders believe their public health service has deteriorated

EDITOR-Having recently returned to Britain from a consultant post in New Zealand, I read with interest Smith's editorial on waiting lists and his reference to New Zealand. ${ }^{1}$ New Zealand introduced the purchaser-provider split and crown health enterprises (equivalent to trust hospitals) in 1993 and attempted to run its health service according to market principles with the corporate ethos.

Yet the perception of most New Zealanders, despite the one newspaper article that Smith quoted, is that their public health service has deteriorated, waiting times for treatment as an inpatient and an outpatient have lengthened, and they are heading for a two tier system. Morale among the medical and allied professions is generally low; it is lowest among those who receive most of their income from the public sector.

One proposal to manage or reduce waiting lists was for crown health enterprises to estimate which patients would not be admitted within a certain time (for example, one year) and return these patients to their general practitioners with instructions for reassessment and re-referral only if their condition worsened. This procedure of course would provide no cure or treatment but waiting lists would fall and be better managed. One effect would be that certain conditions (for example, varicose veins) would hardly ever be dealt with at the public hospitals but would gravitate to the private sector. One surgical colleague commented that a further effect of this policy would be that juniors would receive little exposure to dealing with these conditions.

I would therefore caution readers not to believe that the New Zealand model is perfect and is "light years" ahead of the British model. I agree entirely with the view that waiting lists are a form of rationing and are rough justice for all in that priority is based on clinical grounds. They are by no means the only variable indicating the "health" of the health service, but they are one variable that the public understands and believes in; to dismiss or discount them just because they are "unmanageable" is like shooting the messenger because we don't like the message.

Alan Padwell Consultant histopathologist Department of Pathology, Rochdale Healthcare NHS Trust, Birch Hill Hospital, Rochdale OL12 9QB

1 Smith R. New government, same narrow vision. BMJ 1998;316:643. (28 February.)

\section{Ways of assessing capacity to complete an advance directive should be developed}

EDIToR-The green paper Who Decides? highlights two central issues: whether advance directives should have a statutory basis, and how capacity should be assessed in patients who may be unable to make decisions for themselves. ${ }^{1}$ A potentially important problem brings these two issues together: how should doctors assess the capacity of a patient to complete an advance directive?

Healthy people may not be well placed to make decisions concerning their future incompetent selves ${ }^{1}$ because of the difficulty in imagining the range of situations that might befall them. It is likely to be more fruitful for advance directives to be completed at a time when people already have some disease, because this would enable doctors to give guidance about possible future situations. The BMA has argued that dementia is one clinical situation for which advance directives could be useful. ${ }^{3}$ Doctors may therefore need to be able to assess the capacity of people with early dementia to complete an advance directive.

Who Decides? suggests that to have capacity it is necessary not only to understand but also to retain information. Little guidance is given on how long information needs to be retained. If too high a standard is set this criterion could render most people with even early cognitive impairment incompetent. This could compromise the principle, stated in the green paper, of the presumption of capacity in all adult people. We suggest that the standard should be set so that a person who can retain information long enough to reach a thoughtful decision should be considered competent. This time might be as short as 10 minutes.

When an advance directive is being completed it is crucial to assess whether the person is capable of understanding possible future situations. Clinical vignettes have been shown to be an effective and valid basis for assessing competence to consent to 
medical treatment in people with dementia. $^{45}$ With accompanying information sheets and an interviewer who repeats and clarifies parts of the vignette when necessary, tools can be developed that enable some patients with dementia to complete advance directives. Clinicians will need to develop an approach aimed at enabling those with mild cognitive impairment to complete advance directives rather than one that depends on a fully intact memory.

Seena Fazel Wellcome research registrar Tony Hope Director

ETHOX, Division of Public Health and Primary

Health Care, Institute of Health Sciences,

Headington, Oxford OX3 7LF

Robin Jacoby Clinical reader

Section of Old Age Psychiatry, University of

Oxford, Warneford Hospital, Oxford OX3 7JX

1 Lord Chancellor's Department. Who decides? Making decisions on behalf of mentally incapacitated adults. London: HMSO, 1997. (Cm 3803.)

2 Hope RA. Advance directives about medical treatment BMJ 1992;304:398.

3 BMJ 1992;304:398.

4 Fitten LJ, Lusky R, Hamann C. Assessing treatment decision-making capacity in elderly nursing home decision-making capacity in elderly nur

5 Marson DC, Schmitt F, Ingram K, Harrell L. Determining 5 Marson DC, Schmitt F, Ingram K, Harrell L. Determining
the competency of Alzheimer patients to consent to the competency of Alzheimer patients to consent to
treatment and research. Alzheimer Dis Assoc Disord 1994;8 (suppl 4):5-18.

\section{All troops sent to Gulf should be randomised to receive anthrax vaccination or placebo}

EDITOR-The British ministry of defence announced recently that a new group of British troops are to be offered anthrax vaccination in preparation for service in the Gulf..$^{1}$ The secretary of state for defence was vaccinated on camera as part of an effort to convince service personnel and the public that this vaccination is safe.

It would have been far more impressive if the secretary of state for defence had agreed to be publicly randomised to receive active vaccine or placebo. All those randomised (including the secretary of state) could then have been examined in the future and had their health assessed. The suggestion that anthrax vaccination is a cause of chronic health problems ${ }^{23}$ (the so called Gulf war syndrome) could then be confirmed or refuted.

Such experiments should be extended to include all troops sent to the Gulf. The troops should be randomised-as far as this is practically possible and where it is deemed ethical-in a factorial design. They would then receive (or not receive) all the interventions that have been suggested as causes of Gulf war syndrome. Current thinking is clearly in a state of "clinical equipoise" over the issue of such vaccinations; there are those (including the secretary of state for defence) who consider that the potential protection in case of conflict outweighs any risks and, at the other end of the range, those with diametrically opposed views. Although it is unusual to allocate subjects randomly to potentially harmful exposures, it is not without precedent. A study of the adverse effects of exposure to bathing water that randomised participants to bathe or not to bathe was deemed ethical by the Royal College of Physicians.

We believe that the experimental approach that we suggest is likely to shed light on the nature and aetiology of Gulf war syndrome - more so, indeed, than the observational studies that are currently being undertaken.

Andrew R Ness Senior lecturer in epidemiology Ian Harvey Senior lecturer in epidemiology David Gunnell Senior lecturer in epidemiology George Davey Smith Professor in clinical epidemiology

University of Bristol, Bristol BS8 2PR

1 Ministry of Defence. Gulf troops to get anthrax vaccineprotection is paramount says Robertson. London: Ministry of Defence, 1998. (Press release.)

Roberts J Debate over US Gulf war syndrome continues. BMJ 1994:309:1392-3.

US Departint of Defense. Comprehensive clinical eutiaUS Department of Defense. Comprehensine dinical evaluation program for Gulf war veterans. Washington: US Depart-
ment of Defense, 1995 .

4 Freedman B. Equipoise and the ethics of clinical research. N Engl J Med 1987;317:141-5.

5 Kay D, Fleisher JM, Salmon RL, Jones F, Wyer MD, Godfree $\mathrm{AF}$, et al. Predicting likelihood of gastroenteritis from sea bathing: results from randomised exposure. Lance 1994;344:905-9.

\section{Doctors should beware of asking for too high a salary}

\section{Scottish GPs earn less than intended} average net remuneration

EDITOR-In the last paragraph of his letter about doctors' salaries, Baker asked if the profession really wishes to be seen by society in the same light as accountants and lawyers. ${ }^{1}$ I would answer that the profession naturally wishes to retain its individual identity of integrity and responsibility but would nevertheless wish to have at least the same value placed on it as is placed on the legal and accountancy professions.

Though our remuneration improved dramatically after the doldrums of the 1960 s, since 1980 in general practice it has dropped to less than half that of our comparators defined by Pilkington in the report that preceded the introduction of the Doctors' and Dentists' Review Body. ${ }^{2}$

Baker's friend, who may well augment his practice profits from earnings outside the NHS, is both fortunate and exceptional. The average Scottish general practitioner, despite length of service, earns $£ 43245$, which is $93.1 \%$ of intended average net remuneration (£46450 pa)-below the lowest consultant scale of $£ 43750$; consultants will inevitably rise to a minimum of $£ 56470$ after five years. (These figures are calculated from the latest figures for average net income according to government statistical region as the percentage of the British average, the figures used by the Doctors' and Dentists' Review Body for 1997-8 being used.)

One quarter of general practitioners in Highland area who are "induced" (receive "inducement payments" for general practitioners to remain in practices that are no otherwise financially viable) are restricted to practice profits of only $82.4 \%$ of intended average net remuneration. Successive governments have failed to recognise the importance of the old adage "The labourer is worthy of his hire." We are right to seek a fair improvement in our remuneration to secure the high standards already attained and to reverse the worrying decline in morale and recruitment.

Christopher Tiarks Secretary, Highland Area Local Medical Committee

Grianan, Isle of Eigg, Scotland PH42 4RL

1 Baker R. Doctors should beware of asking too high a salary. BMJ 1997;315:954. (11 October.)

2 Royal Commission on Doctors' and Dentists' Remuneration. 1957-1960 report. London: HMSO, 1960. (Pilkington report.)

\section{What is too high a salary?}

EDITOR-In a letter Baker queried the validity of doctors seeking increased remuneration; he told an anecdote about the salary of a recently appointed general practitioner who was being paid $£ 90000$ - $£ 10000$ a year, albeit in an admittedly "not typical" and "well run" practice. ${ }^{1}$ We are not told whether these are gross or net earnings and, on the assumption that they are net earnings, whether this sum reflects income purely for general medical services or includes external and private fees. Even if it includes only external fees, there are circumstantial variables to be taken into account, including high list size, deprivation payments, dispensing income, and fundholding management fees, which are not necessarily universally available.

There will be many disappointed potential general practitioners if they expect such a salary. I doubt whether Baker would have been so charitable if I had written some 25 years ago to suggest that all surgeons were overpaid. One consultant surgeon, whose houseman I then was, had just earned double my annual salary in one day: he had performed a prostate operating list in the morning (the list had included two laryngectomies at $£ 500$ each) and a private/NHS list in the afternoon with several private consultations in the evening before going out to dinner. Simple arithmetic suggested that he earned over $£ 3000$ for that day, with the potential for reaching Baker's excessive figure for today of $£ 100000$ in a month.

I am no different from lawyers and accountants, some of whom earn less and some more than I do, but we all wish to receive adequate and appropriate remuneration for our skills and efforts. The partnership in which I work-of four general practitioners-paid our accountants some $£ 4000$ last year, or $£ 1000$ a head; the population of Birmingham (one million) received full general medical services at the same time at a cost of about $£ 60 \mathrm{~m}$ or $£ 60$ a head (or just over $£ 1$ or 10 cigarettes a week). Society values what it pays for: I see no reason to be considered a special case just because I happen to enjoy being a doctor.

P G Houghton General practitioner Greenbank Surgery, Birmingham B28 8BG

1 Baker R. Doctors should beware of asking for too high a salary. BMJ 1997;315:954. (11 October.) 